\title{
Pulmonary hypertension in patients with chronic myeloproliferative disorders
}

\author{
Y. Adir* and M. Humbert ${ }^{\#}$
}

\begin{abstract}
Pulmonary hypertension $(\mathrm{PH})$ is a severe haemodynamic disorder in which the pulmonary artery pressure is persistently elevated, leading to right-sided heart failure and death. Recently, chronic myeloproliferative diseases associated with pulmonary hypertension were included in the group 5 category, corresponding to $\mathrm{PH}$ for which the aetiology is unclear and/or multifactorial.

In this review we will describe the distinct forms of $\mathrm{PH}$ in the context of the myeloproliferative diseases chronic thromboembolic pulmonary hypertension and pre-capillary PH mimicking pulmonary arterial hypertension. The epidemiology, mechanisms and treatment approaches will be discussed.
\end{abstract}

KEYWORDS: Chronic thromboembolic pulmonary hypertension, essential thrombocytosis, myeloproliferative disorders, polycythaemia vera, pulmonary hypertension, pulmonary venoocclusive disease

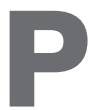
ulmonary hypertension $(\mathrm{PH})$ is defined as a group of diseases characterised by an elevated mean pulmonary artery pressure $(P$ pa $) \geqslant 25 \mathrm{mmHg}$ at rest [1-3]. The clinical classification of $\mathrm{PH}$ comprises apparently heterogeneous conditions which share comparable clinical presentations, pathophysiology and management. The first category of the clinical classification termed "pulmonary arterial hypertension (PAH)" includes idiopathic PAH (IPAH), hereditable $\mathrm{PAH}$ and $\mathrm{PAH}$ related to risk factors or associated conditions [2], such as connective tissue diseases, congenital heart diseases, portal hypertension, HIV infection and exposure to drugs and toxins such as fenfluramines (table 1). In the 4th World Symposium on PH held in 2008 [2], chronic myeloproliferative diseases (CMPD) associated with $\mathrm{PH}$ were included in the group 5 category, corresponding to $\mathrm{PH}$ for which the aetiology is unclear and/or multifactorial [3]. As emphasised in a recent article by SIMONNEAU et al. [3], it is important to better characterise this variant of the disease in order to provide better tools to clinicians who treat these patients with severe comorbidities.

The World Health Organization classification of CMPD includes five groups of haematopoietic disorders, some of which are rare or poorly characterised (table 2) [4]. The origin of CMPD is a multi-potent haematopoietic progenitor cell with overproduction of one or more of the formed elements of the blood without significant dysplasia. There is a predilection to extramedullary haematopoiesis, myelofibrosis and transformation at varying rates to acute leukaemia. CMPD include chronic myelogenous leukaemia, chronic neutrophilic leukaemia and chronic eosinophilic leukaemia (which primarily express a myeloid phenotype and polycythaemia vera), idiopathic myelofibrosis, and essential thrombocytosis in which erythroid or megakaryocytic hyperplasia predominates. This phenotypic heterogeneity has a genetic basis; chronic myelogenous leukaemia is the result of the balanced translocation between chromosomes 9 and 22 (Philadelphia chromosome) [5], and polycythamia vera, idiopathic myelofibrosis and essential thrombocytosis are characterised by different rates of expression of a JAK2 mutation, V617F [6]. This essential distinction is also reflected in the natural history of chronic myelogenous leukaemia, chronic neutrophilic leukaemia and chronic eosinophilic leukaemia, which is usually measured in years, and their high rate of transformation into acute leukaemia. In contrast, polycythaemia vera, idiopathic myelofibrosis and essential thrombocytosis have relatively indolent clinical courses that may be interrupted by recurrent thrombohaemorrhagic complications. The incidence of

\section{AFFILIATIONS}

*Pulmonary Divison, Carmel Medical Center, Faculty of Medicine, Technion, Institute of Technology, Haifa, Israel.

\#Vascular Pulmonary Diseases Center, Dept of Pulmonary Diseases, Hopitaux de Paris, Universite, ParisSud, Clamart, France.

\section{CORRESPONDENCE}

Y. Adir

Pulmonary Divison

Carmel Medical Center

7 Michal St.

Haifa

Israel

E-mail: adir-sh@zahav.net.il

Received:

Nov 062009

Accepted after revision:

Jan 042010 
CMPD is estimated at between six and nine new cases per 100,000 each year. New cases most commonly occur between the age of 40-60 yrs. Pulmonary complications of CMPD are infrequent and are usually caused either by infection or by venous thromboembolic events. Pulmonary or pleural extramedullary haemopoiesis is a rare complication that may be associated with myelofibrosis $[7,8]$.

\section{EPIDEMIOLOGY}

The possible association of PH with CMPD has been suggested by case reports and small case series [9, 10, 11-22]. However, the exact incidence and prevalence of $\mathrm{PH}$ in this population remains poorly defined. Furthermore, since the clinical signs of

\section{TABLE 1 Updated clinical classification of pulmonary arterial hypertension (Dana Point, 2008) [2]}

\section{Pulmonary arterial hypertension}

1.1 Idiopathic pulmonary arterial hypertension

1.2 Heritable

1.21 BMPR2

1.2.2 ALK1, endoglin (with or without hereditary haemorrhagic telangiectasia)

1.2.3 Unknown

1.3 Drug and toxin-induced

1.4 Associated with

1.4.1 Connective tissue diseases

1.4.2 HIV infection

1.4.3 Portal hypertension

1.4.4 Congenital heart diseases

1.4.5 Schistosomiasis

1.4.6 Chronic haemolytic anaemia

1.5 Persistent pulmonary hypertension of the newborn

1 '. Pulmonary veno-occlusive disease and/or pulmonary capillary haemangiomatosis

\section{Pulmonary hypertension owing to left heart disease}

2.1 Systolic dysfunction

2.2 Diastolic dysfunction

2.3 Valvular disease

3. Pulmonary hypertension owing to lung diseases and/or hypoxia

3.1 Chronic obstructive pulmonary disease

3.2 Interstitial lung disease

3.3 Other pulmonary diseases with mixed restrictive and obstructive pattern

3.4 Sleep-disordered breathing

3.5 Alveolar hypoventilation disorders

3.6 Chronic exposure to high altitude

3.7 Developmental abnormalities

\section{Chronic thromboembolic pulmonary hypertension}

5. Pulmonary hypertension with unclear multifactorial mechanisms

5.1 Haematological disorders: myeloprolifearative disorders, splenectomy

5.2 Systemic disorders: sarcoidosis, pulmonary Langerhans cell

histocytosis: Iymphangioleiomyomatosis, neurofibromatosis, vasculitis

5.3 Metabolic disorders: glycogen storage disease, Gaucher disease,

thyroid disorders

5.4 Others: tumoural obstruction, fibrosing mediastinitis, chronic renal failure on dialysis

Alk1: activin receptor-like kinase type 1; BMPR2: bone morphogenetic protein receptor protein type 2 .
PH appear at an advanced stage of the disease and, in some cases, the diagnosis of CMPD is difficult to establish in the context of chronic hypoxaemia, the prevalence of $\mathrm{PH}$ is probably underestimated in this patient population. An early study [9] has evaluated cardiac involvement in 30 patients with CMPD (18 females and 12 males). 18 patients had polycythaemia vera, eight essential thrombocytosis and four angiogenic myeloid metaplasia. $\mathrm{PH}$ unrelated to valvular disease was identified in four $(13 \%)$ out of 30 patients. GARYPIDOU et al. [10] have described the prevalence of PH in a cohort of 24 patients with CMPD. Two patients had polycythaemia vera, 14 essential thrombocytosis, six agnogenic myeloid metaplasia and two chronic myelogenous leukaemia. A diagnosis of $\mathrm{PH}$ was proposed if the estimated right ventricular systolic pressure (Prvs) was $>35 \mathrm{mmHg}$ on Doppler echocardiography. $10(41.7 \%)$ patients, four males and six females, had PH with a mean Prvs of $42 \mathrm{mmHg}$ (37$70 \mathrm{mmHg}$ ). None of the parameters analysed in the study which included age, sex, presence of splenomegaly, type, duration and age at diagnosis of CMPD, presence of symptoms, haemoglobin levels, white blood cell or platelet count was predictive of the presence of PH. However, the rate of patients with $\mathrm{PH}$ may be overestimated since no gold standard haemodynamic confirmation of $\mathrm{PH}$ was obtained and secondary causes, such as left ventricular dysfunction or high cardiac output state, were not excluded [23, 24]. AltinTAS et al. [11] reported on the incidence of $\mathrm{PH}$ in 46 patients with essential thrombocytosis. A diagnosis of $\mathrm{PH}$ was proposed if a patient had a Prvs $>35 \mathrm{mmHg}$ on transthoracic echocardiography. PH was found in $22(47.8 \%)$ out of 46 patients with essential thrombosis and significantly higher platelet counts were observed in patients with essential thrombocytosis and PH. Another study by GuPTA et al. [12], which also did not use right heart catherisation ( $\mathrm{PH}$ was evaluated by Prvs

\section{TABLE 2 World Health Organization classification of chronic myeloproliferative diseases}

\section{Myeloproliferative neoplasms}

1.1 Chronic myelogenous leukaemia, BCR-ABL1 positive

1.2 Polycythaemia vera

1.3 Essential thrombocythaemia

1.4 Primary myelofibrosis

1.5 Chronic neutrophilic leukaemia

1.6 Chronic eosinophilic leukaemia, not otherwise specified (CEL-NOS)

1.7 Mast cell disease

1.8 Myeloproliferative neoplasms, unclassifiable

2. Myeloid and lymphoid neoplasms with eosinophilia and abnormalities of PDGFRA, PDGFRB, and FGFR1

3. Myelodysplastic syndromes/myeloproliferative neoplasms

3.1 Chronic myelomonocytic leukaemia

3.2 Juvenile myelomonocytic leukaemia

3.3 Atypical chronic myeloid leukaemia, BCR-ABL negative

3.4 Myelodysplastic syndromes/myeloproliferative neoplasms, unclassifiable

4. Myelodysplastic syndromes

5. Acute myeloid leukaemia

BCR-ABL: break-point mutation-Abelson; PDGFRA: $\alpha$-type platelet-derived growth factor receptor; PDGFRB: $\beta$-type platelet-derived growth factor receptor; FGFR1: fibroblast growth factor receptor 1 . 
$>35 \mathrm{mmHg}$ on transthoracic echocardiography), described $\mathrm{PH}$ in $12(48 \%)$ out of 25 patients with CMPD. There was no relationship between $\mathrm{PH}$ and age at diagnosis, duration of disease, platelet count and haematocrit level. Since angiogenesis is believed to contribute to the pathogenesis of both $\mathrm{PH}$ and CMPD, a recent study has investigated the association of $\mathrm{PH}$ and primary myelofibrosis [13]. The study group consisted of 36 patients, 22 with primary myelofibrosis, seven with myelofibrosis developing from polycythaemia vera and seven with myelofibrosis progressing from essential thrombocytosis. $\mathrm{PH}$ (Prvs $>35 \mathrm{mmHg}$ on transthoracic echocardiography) was found in $13(36 \%)$ patients [13].

However, all these studies have major limitations, as the diagnosis of $\mathrm{PH}$ was not established as recommended by expert guidelines $[23,24]$. Therefore, the rate of patients with $\mathrm{PH}$ may be overestimated, as elevated Prvs or systolic P pa might not be confirmed by invasive measures, or could be due to other causes such as left sided heart disease. Indeed REISNER et al. [9] demonstrated that heart disease is common in patients with CMPD, and they reported that 19 out of 30 patients had valvular lesions particularly when their past history was complicated by a thromboembolic event. In addition, some patients may have hypermetabolic state resulting in high cardiac output and passive elevation of the $P$ pa without elevation in pulmonary vascular resistance. Thus, transthoracic Doppler echocardiography can serve only as a screening tool and a right heart study with full haemodynamic evaluation is mandatory for the correct diagnosis of $\mathrm{PH}[23,24]$.

Two major distinct clinical forms of $\mathrm{PH}$ have been described in patients with CMPD; chronic thromboembolic PH (CTEPH) and pre-capillary $\mathrm{PH}$ mimicking PAH. GUILPAIN et al. [14] described six patients with CTEPH (five presented with polycythaemia vera and one with essential thrombocytosis). The diagnosis of CTEPH was simultaneous to that of CMPD in all post-embolic cases, and $\mathrm{PH}$ revealed the underlying, untreated myeloproliferative disorder. As a result these patients had significantly higher haematocrit levels than patients with pre-capillary $\mathrm{PH}$ mimicking PAH. Conversely, pre-capillary $\mathrm{PH}$ mimicking $\mathrm{PAH}$ associated with CMPD is diagnosed late in the course of the disease [14-16]. In the report by DiNGLi et al. [15], pre-capillary $\mathrm{PH}$ mimicking PAH was diagnosed a median of 8 yrs after recognition of the myeloproliferative disorder (0-26 yrs), while in study by GuILPAIN [14] pre-capillary $\mathrm{PH}$ mimicking $\mathrm{PAH}$ occurred later in the evolution of the CMPD (polycythaemia vera in three patients and essential thrombocytosis in one) with a median of 162 months (13.5 yrs) and it was associated with myeloid metaplasia.

\section{CTEPH}

\section{Aetiology}

The suggested mechanisms for the development of CTEPH are shown in figure 1.

The clinical course of CMPD, and particularly of polycythaemia vera and essential thrombocytosis, is characterised by a thrombophilic state that manifests with microcirculatory disturbances and arterial and venous thromboses [25]. These include ischaemic stroke which constitutes $30-40 \%$ of all thrombotic events in polycythaemia vera patients, myocardial infarction, peripheral arteries occlusion and deep venous thrombosis of lower limbs, which may cause pulmonary embolism [26]. The rate of thrombotic events in polycythaemia vera and essential thrombocytosis is $22-38.6 \%$ and $13-29.4 \%$, respectively [21, 22 25-32]. Two thirds of the thrombotic events are arterial and about one third correspond to venous thrombosis in polycythaemia vera, while in essential thrombocytosis most of the thrombotic events are arterial [25-34]. In a retrospective analysis of 260 patients with CMPD [27], during a median follow-up of 31 months, thrombotic events were diagnosed in $36 \%$ of patients with polycythaemia vera and $20 \%$ with essential thrombocytosis. Elevated red blood cell counts, higher haemoglobin levels and increased percentage of nucleated neutrophils at the time of diagnosis and older age were associated with thrombosis. In a retrospective study of the Gruppo Italiano Studio Policitemia [28], patients with polycythaemia vera were included and had been followed for 20 yrs: $41 \%$ of patients had at least one thrombotic event, which occurred either at presentation or before diagnosis in $64 \%$ of cases. Thrombotic events were seen more frequently in the 2 yrs preceding the diagnosis and were associated with a higher morbidity and mortality. The incidence of thrombosis during follow-up was $3.4 \%$ per year. Older patients or those with a history of thrombosis had a higher risk for thrombosis.

The high haematocrit values in polycythaemia vera results in blood hyperviscosity [35]. In the venous circulation, characterised by a low shear rate state, hyperviscosity may cause a

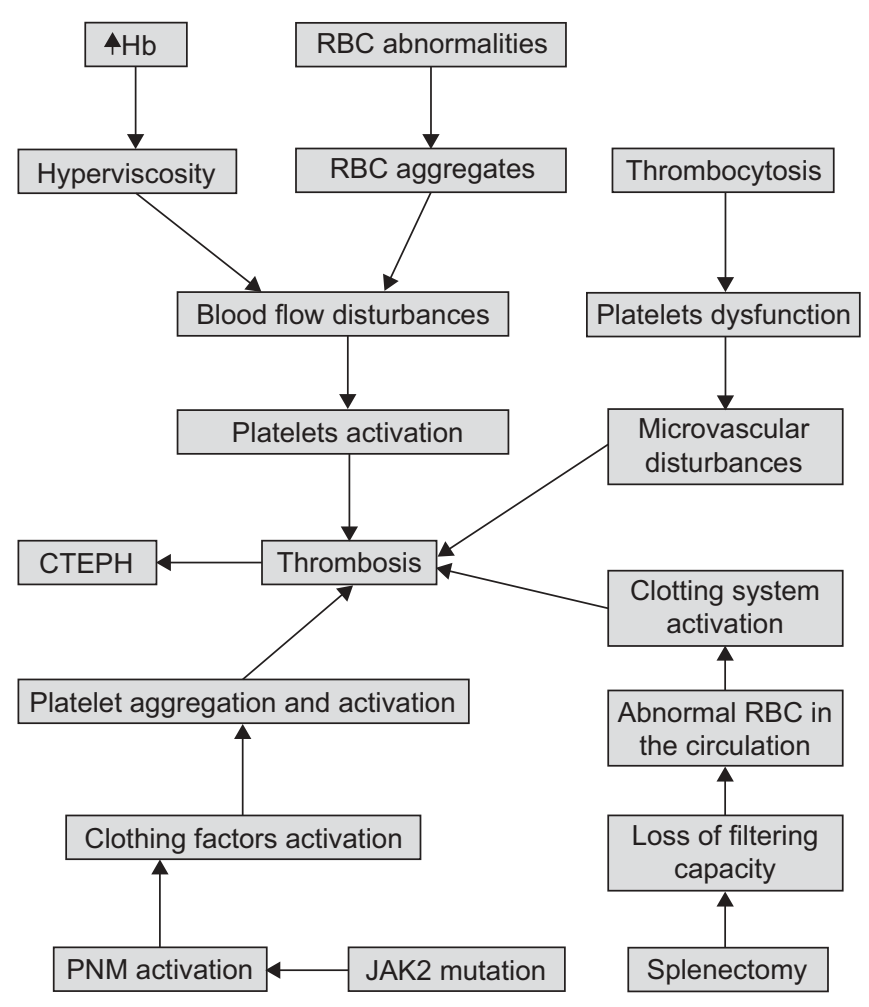

FIGURE 1. Suggested mechanisms for the development of chronic thromboembolic pulmonary hypertension (CTEPH) in patients with chronic myeloproliferative disorders. Hb: haemoglobin; RBC: red blood cells; PMN: polymorphonuclear cells. 
major disturbance to blood flow and increased risk of thrombosis. At higher shear rates in the arterial circulation the rise in red cell mass displaces the platelets towards the vessel wall, increasing platelet activation and platelet-platelet interactions [21]. Furthermore, red blood cell abnormalities which occur in polycythaemia vera and essential thrombocytosis may lead to the formation of red blood cell aggregates that directly contribute to flow disturbance and thrombosis and platelet activation, especially in small vessels [25, 36, 37].

Erythropoietin-independent erythroid colony (EEC) formation is used as one of the criterion for the diagnosis of polycythaemia, although spontaneous EEC formation has insufficient diagnostic specificity and sensitivity as isolated parameters to differentiate between polycythaemia vera and secondary erythrocytosis [4]. Spontaneous EEC formation may be associated with thrombosis, particularly of hepatic veins, in the absence of other peripheral blood abnormalities and the presence of EEC leads to the diagnosis of primary myeloproliferative disorder in $78 \%$ of cases with apparent idiopathic Budd-Chiari syndrome, and in about half of patients with portal, splenic and/or mesenteric vein thrombosis [38, 39]. Another study did not find EEC as a surrogate marker of thrombotic risk (not specifically related to the splanchnic vessels) in male subjects with essential thrombocytosis [40]. In the study of GUILPAIN et al. [14] the diagnosis of CTEPH (fig. 2) and CMPD was made simultaneously in all patients, suggesting that CTEPH could be the first manifestation of CMPD and EEC formation tests might be of interest in order to unmask as yet unrecognised CMPD in CTEPH patients.

It has been suggested that thrombocytosis can contribute to the vascular events of essential thrombocytosis or polycythaemia vera, since platelet count reduction was reported to lower the risk of microcirculatory disturbances and the antithrombotic efficacy of chemotherapy in high-risk essential thrombocytosis subjects has been clearly demonstrated [25, 32, 41, 42]. Essential thrombocytosis patients with microvascular disturbances have decreased platelet survival and evidence for platelet-mediated thrombotic processes, such as increased urinary thromboxane B2 [21]. Inhibition of platelet cyclooxygenase- 1 by aspirin is followed by improving microvascular disturbances with correction of shortened platelet survival time and reduction of thromboxane B2 excretion to normal levels [25 41, 43]. In polycythaemia vera associated with thrombocythaemia, hyperviscosity aggravates the platelet-mediated microvascular disturbances of thrombocythaemia and may cause major arterial and venous thrombotic complications. Correction of hyperviscosity by phlebotomy fails to prevent platelet-mediated microvascular alteration because thrombocythaemia persists [25, 44]. However, no correlation was demonstrated in other studies between the degree of thrombocytosis, the presence of platelet dysfunction and the risk of thrombosis in polycythaemia vera [25, 42] In addition, in essential thrombocytosis the correlation with the platelet count appears to be unclear and the antithrombotic effects of chemotherapy may be related to an effect on leukocyte count and, possibly, on platelet and leukocyte activation. Furthermore, marked thrombocytosis can favour haemorrhagic rather than thrombotic manifestations in essential thrombocytosis patients [25, 42, 45].
The increase in white blood cell count is a risk factor for thrombosis in patients with polycythaemia vera and essential thrombocytosis. Previous studies [25, 31, 46] demonstrated an ongoing state of polymorphonuclear leukocytes (PMN) activation, which correlates with increased plasma level markers of clotting activation. PMN activation and increased adhesion of PMN to endothelial cells and platelets support the hypothesis of an involvement of PMN in the pathogenesis of the hypercoagulable state of patients with essential thrombocytosis and polycythaemia vera.

Recently, the presence of the acquired gain-of-function V617F mutation in the tyrosine kinase JAK-2 gene has been demonstrated in PMN and platelets of patients with CMPD [46, 47]. The frequency of the JAK2 mutation is close to $95 \%$ and $50 \%$ in polycythaemia vera and essential thrombocytosis, respectively [47-49]. In addition, essential thrombocytosis patients harbouring a JAK2 mutation appear to have a "polycythaemia veralike" phenotype with increased rate of venous thrombosis [50]. Several studies reported on the association of JAK2 mutation and thrombosis at uncommon sites and JAK2 mutation may be associated with increased incidence of thrombosis with no relation to the CMPD. Patients with the JAK2 mutation have increased PMN activation, with platelets aggregation and activation. This may contribute to increased susceptibility to thrombotic events in patients with CMPD [25, 51, 52]. Diagnostically in patients with splanchnic vein thrombosis the work-up should include a search for the JAK2 mutation [53]. However, in patients with thrombosis outside the splanchnic system and no evidence for CMPD, the JAK2 mutation is infrequently detected and, at present, testing for this mutation is not indicated [54].

In 1966, a retrospective study evaluating 80 splenectomised patients suffering from various types of hereditary haemolytic anaemia found that $13 \%$ of the splenectomised patients had thrombocytosis [55]. A more recent review of the literature reports that thromboembolic complications following splenectomy for haematological diseases occur in up to $10 \%$ of patients and may range from portal vein thrombosis to pulmonary embolism and deep vein thrombosis [56-59]. In a prospective case-control study of 109 patients with CTEPH, BONDERMAN
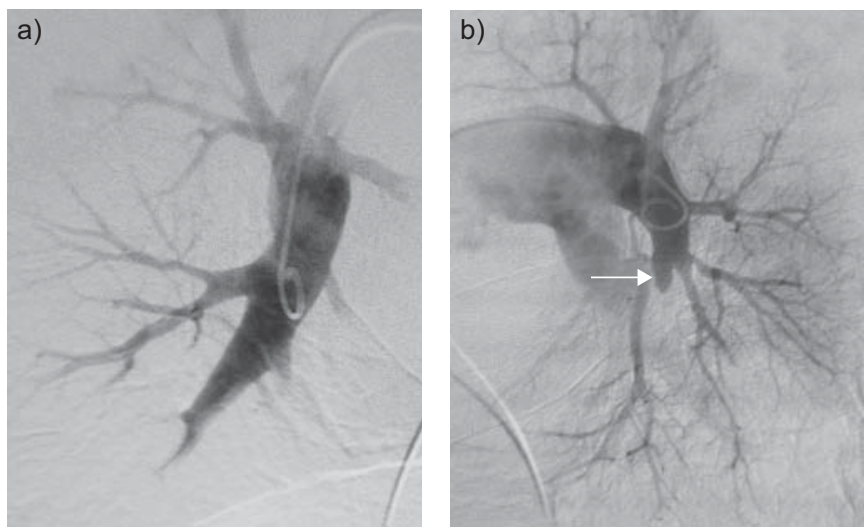

FIGURE 2. Pulmonary angiogram in a patient with polycythaemia vera showing a) the right and b) the left lateral view. The lateral views show evidence of chronic thromboembolic pulmonary hypertension. The patient has been successfully treated with pulmonary endarterectomy. The arrow indicates a pouching defect. 
et al [60] found that splenectomy was an independent risk factor for CTEPH.

The pathogenesis of thromboembolism after splenectomy is poorly understood. The transient thrombocytosis expected immediately after splenectomy is usually not associated with thrombotic events and patients may develop CTEPH several years after splenectomy when thrombocytosis is no longer present. Furthermore, many patients have post-splenectomy thrombocytosis for many years without developing signs of thromboembolism suggesting that post-splenectomy thrombocytosis should not be the only factor predisposing patients to thrombosis, although local pulmonary platelets activation and thrombin generation may play a role in the pathogenesis of CTEPH [60-63].

One explanation for the increased thrombotic complication after splenectomy may be the loss of the filtering function of the spleen which allows abnormal red blood cells to remain in the peripheral circulation $[61,62]$. It is well known that anionic phospholipids of the red blood cell membrane, which are localised on the inner membrane leaflet, can activate the coagulation system. Abnormal exposure of these phospholipids (such as phosphatidylserine) would promote activation of the coagulation process by fixation of enzymatic complexes. Indeed it has been shown in patients with thalassaemia that the number of red blood cells with modified phosphatidylserine expression was 20 times higher after splenectomy [64-66].

In patients with CMPD, splenectomy results in worsening extramedullary haematopoiesis with the potential for pulmonary infiltration. In addition, the platelets in CMPD are functionally abnormal and in concert with the marked elevations in platelet counts it may explain the difference in the interval to the development of $\mathrm{PH}$ which is much shorter in patients with CMPD [25]. GUILPAIN et al. [14] reported on 10 cases with $\mathrm{PH}$ associated with CMPD. In six of the cases the diagnosis of CTEPH was made simultaneously to that of CMPD suggesting that CTEPH could be the first manifestation of myeloproliferative disorder. In their study the platelet count was not different between patients with CTEPH and PAH associated with CMPD's. Elevated haematocrit was significantly associated with CTEPH compared to the four patients with pre-capillary PH mimicking PAH associated with CMPD suggesting that elevated haematocrit may contribute to the developments of pulmonary artery thrombosis. Interestingly, none of the patients with CTEPH had undergone splenectomy.

\section{Treatment}

Treatment of arterial and venous thromboses in polycythaemia vera and essential thrombocytosis patients should not differ from that recommended in the general population [67].

Pulmonary endarterectomy is the treatment of choice in patients with CTEPH [68]. In cases which are inaccessible to surgery, medical therapy including diuretics, anticoagulants, and specific PAH therapy should be considered [69-74]. To date, no data on specific PAH therapy is available for patients with CTEPH associated with CMPD.

In patients with high thrombotic risk a cytoreductive therapy with hydroxyurea is recommended $[75,76]$. Previous studies demonstrated that hydroxyurea reduces the risk of thrombosis in such high-risk patients [25]. In the PT1 trial [77], the efficacy and safety of hydroxyurea plus aspirin were significantly higher than those of anagrelide plus aspirin with a reduced number of both thromboses and bleedings in this group. The high antithrombotic efficacy of hydroxyurea can be attributed to its effect on leukocyte count and, possibly, on leukocyte activation [78]. The effectiveness of antiplatelet agents in reducing the incidence of vascular events was investigated in several studies. In the ECLAP study [79] a significant reduction of the combined risk of cardiovascular death, non-fatal myocardial infarction, non-fatal stroke and major venous thrombosis without a significant increase of the bleeding risk was demonstrated supporting the use of low-dose aspirin in polycythaemia vera subjects having no contraindication. In essential thrombocytosis, the use of aspirin is controversial since the efficacy and safety of low-dose aspirin has been evaluated only in small-size studies and the potential increased risk of bleeding $[25,80]$.

\section{PRE-CAPILLARY PH MIMICKING PAH \\ Aetiology}

The suggested potential mechanisms for the development of PAH-like disease associated with CMPD are shown in figure 3.

Several causal factors may be implicated in the pathogenesis of PAH in patients with CMPD. Portal hypertension is a cause of $\mathrm{PAH}$ and is a well-known complication of myeloid metaplasia with myelofibrosis [81, 82]. WARD et al. [83] reported that $17 \%$ of patients with myeloid metaplasia and myelofibrosis develop portal hypertension. First, this may explain the coexistence of the conditions in some patients. DiNGLi et al. [15] reported that two out of 26 patients with $\mathrm{PH}$ associated with CMPD had portal hypertension with oesophageal varices and in the study by GUILPAIN [14] only one out of 10 patients had portal hypertension with oesophageal varices. Secondly, the use of chemotherapy in these conditions may result in pulmonary damage or promote pulmonary veno-occlusive disease, a rare variant of $\mathrm{PH}$. Pulmonary veno-occlusive disease is increasingly recognised as a cause of $\mathrm{PH}$ occurring during the course of cytotoxic chemotherapy and haematopoietic stem cell transplantation [84]. A recent study [85] reports a case of biopsy-proven pulmonary veno-occlusive disease as a cause of severe $\mathrm{PH}$ in a patient suffering from a CMPD (fig. 4). The introduction of anagrelide several weeks before the development of the symptoms may suggest that this drug might be, at least partially, involved in the pathogenesis of the development of pulmonary veno-occlusive disease. A recent report described six patients with CMPD and elevated $P$ pa on echocardiography [86]. The findings of a low resting saturation, low diffusion capacity for carbon monoxide in concert with the presence of centrilobular ground-glass opacities, septal lines and lymph node enlargement on high-resolution computed tomography of the chest (fig. 5) are highly suggestive of a diagnosis of pulmonary veno-occlusive disease [87]. Pulmonary veno-occlusive disease was diagnosed late in the course of the disease and the prognosis was poor [88]. DINGLI et al. [15] reported that seven out of 26 patients with CMPD and elevated $P$ pa on echocardiography were treated before or after the diagnosis of $\mathrm{PH}$ with anagrelide, but the small number of patients precludes any statistical analysis and most of the patients developed $\mathrm{PH}$ without any exposure to the drug. 


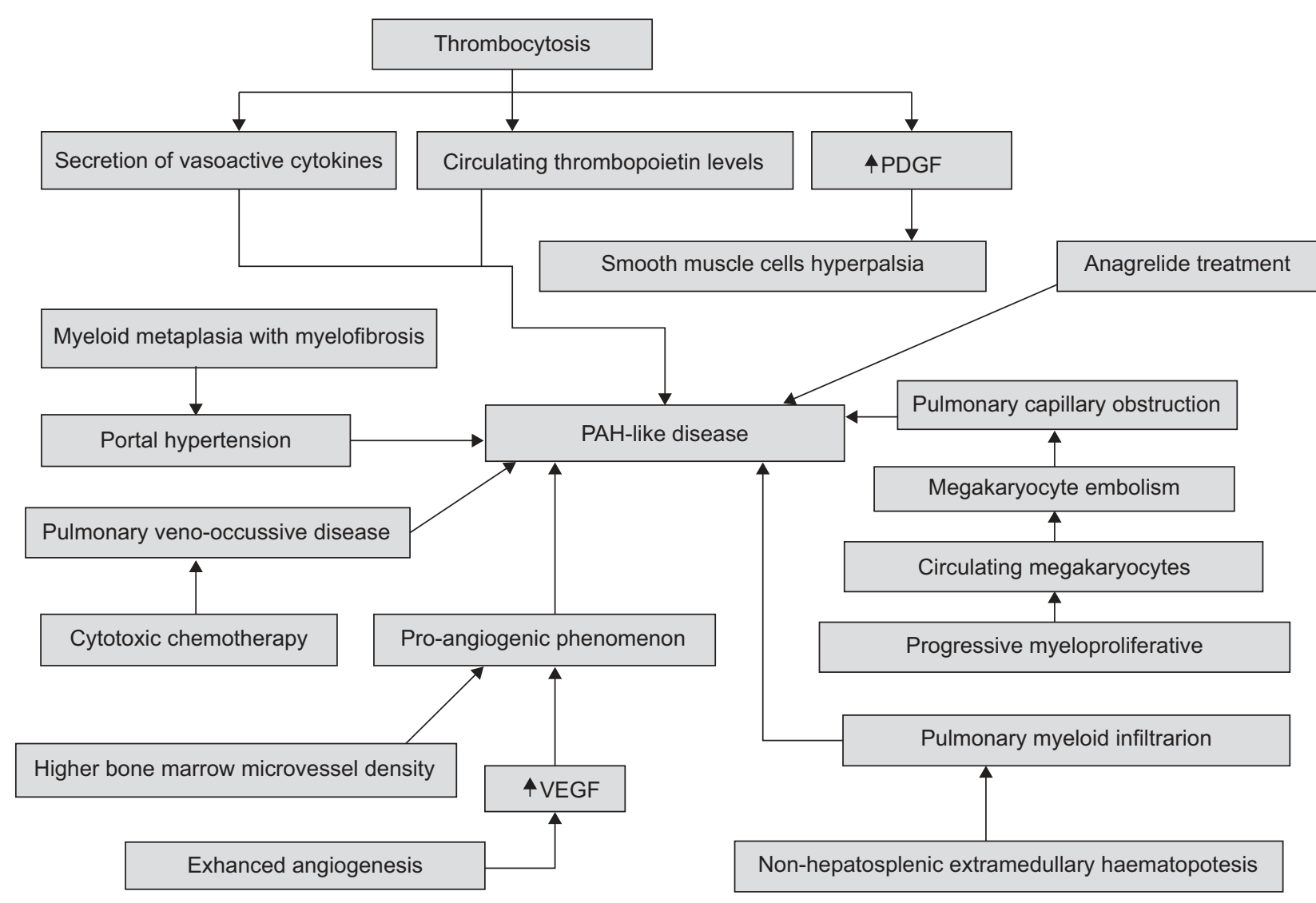

FIGURE 3. Suggested mechanisms for the development of pulmonary arterial hypertension (PAH)-like disease associated with chronic myeloproliferative disorders PDGF: platelet derived growth factor; VEGF: vascular endothelial growth factor.

Tumour microembolism leading to $\mathrm{PH}$ may be associated with various tumours [89]. In patients with progressive myeloproliferative syndrome, megakaryocyte embolism of pulmonary vessels may be caused by translocation of megakaryocytes from the bone marrow, spleen or liver to the lungs, finally leading to PH. Several case reports [87-89] describe patients with CMPD and $\mathrm{PH}$, with pathological examination of the lung demonstrating an obstruction of the small vessels by conglomerates of megakaryocytes. MARVIN et al. [17] reported a patient with myeloid metaplasia, $\mathrm{PH}$ and right heart failure, thrombocytosis and circulating megakaryocytes after splenectomy. The authors postulated that the cause of $\mathrm{PH}$ was pulmonary capillary obstruction by megakaryocytes with stasis and secondary microthrombosis. HiBBIN et al. [90] reported that myelofibrosis and myeloid metaplasia is associated with increased numbers of circulating megakaryocytes and myeloid progenitor cells which are poorly deformable and are much larger than the diameter of alveolar capillaries. Therefore, these cells may occlude the pulmonary microvasculature and secrete vasoactive cytokines, which may contribute to the development of PH. Recently, a positive correlation between thrombopoetin levels and systolic Ppa was shown. Since patients with CMPD exhibit increased circulating thrombopoietin levels, thrombopoetin may be related to the pathogenesis of $\mathrm{PH}$ in this patient population [91].

Non-hepatosplenic extramedullary haematopoiesis is rare and often associated with myelofibrosis and myeloid metaplasia but it can also accompany other disorders such as polycythaemia vera and melodysplastic syndrome. It is preferentially affects the thoracic spinal region but can involve other organs, such as the lung and the pleura [92]. Pulmonary myeloid infiltration during the chronic phase of agnogenic myeloid metaplasia and leukaemic infiltration during the acute transformation of the disease may be related to the development of PH. STEENSMA et al. [93] described four patients with myelofibrosis with myeloid metaplasia who developed severe $\mathrm{PH}$. In two of the patients technetium-99m sulphur colloid scintigraphy demonstrated diffuse pulmonary uptake consistent with extramedullary haematopoiesis. WEINSCHENKER et al. [94] reported the case of a 76-yr-old female with myelofibrosis and $\mathrm{PH}$ in whom an open lung biopsy confirmed pulmonary extramedullary haematopoiesis.

Blood cell proliferation in patients with CMPD may have a major role in pathogenesis of PH. DiNGLY et al. [15] reported a correlation between Prvs and platelet count in patients with myeloid metaplasia and essential thrombocythaemia, and with haemoglobin levels in patients with polycythaemia vera. As mentioned previously, platelets seem to play a central role in the aetiology of PH. Platelet-derived growth factor released from activated platelets is a strong stimulus for smooth muscle hyperplasia $[95,96]$, and in an animal model of PH the control of the platelet count slows down the development of $\mathrm{PH}$ [97]. Previous case studies have described an association between platelet counts, pulmonary pressures and symptoms. MARVIN 

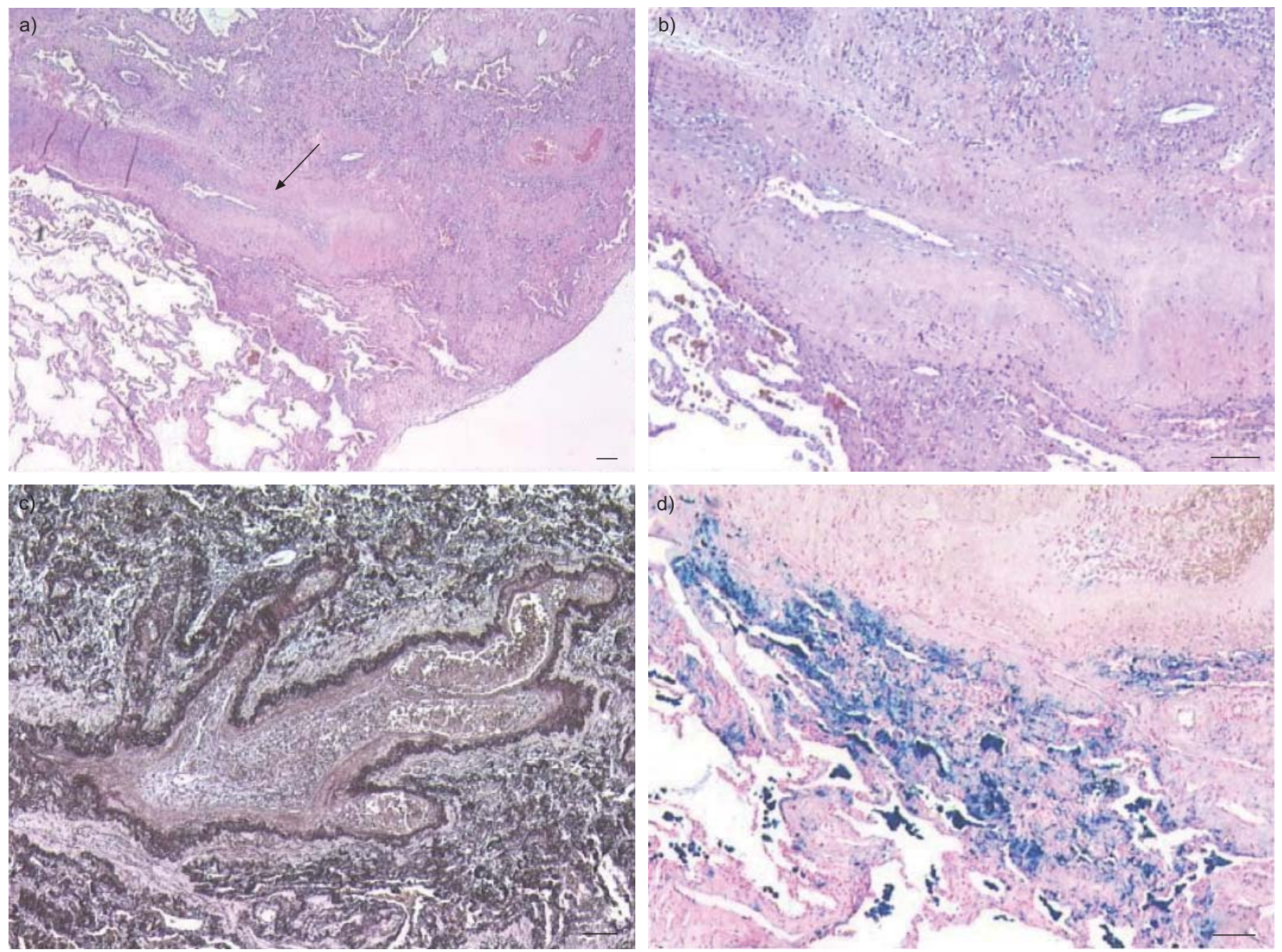

FIGURE 4. Pulmonary veno-occlusive disease in a patient with myeloproliferative disease. a) Low-power view showing thickening and partial luminal obliteration of a medium-sized vein in an interlobular septum (arrow), and partial fibrous obliteration of the surrounding lung parenchyma (haematoxylin-eosin stain). b) High-power view of the obliterated vein (haematoxylin-eosin stain). c) Elastin stain showing duplication of the elastic lamina, indicative of arteriolisation of the vein (orcein stain). d) Perl's iron stain showing coarse iron deposits in the pulmonary interstitium, as well as in alveolar macrophages. Scale bars $=100 \mu$ m. Reproduced from [80] with permission from the publisher.

and SPELlBERG [17] reported that cytoreductive therapy reversed $\mathrm{PH}$ and right heart failure in a 72-yr-old patient with myeloid metaplasia by decreasing the platelet count. However, in the study by DINGLI [15], 12 out of 26 patients were treated with aspirin before $\mathrm{PH}$ was diagnosed suggesting that antiagregant agents, as opposed to cytoreductive therapy, probably have no effect in preventing or reversing $\mathrm{PH}$.

Finally, recent studies have suggested that enhanced angiogenesis in the peripheral blood and bone marrow might be a possible pathogenetic link between CMPD and PH. In this study patients with primary myelofibrosis and $\mathrm{PH}$ had higher bone marrow microvessel density and vascular endothelial growth factor levels suggesting the presence of a proangiogenic phenomenon $[98,99]$. Other studies demonstrated that distinctive features of myelofibrosis associated with $\mathrm{PH}$ include normal or low circulating CD34 cell count, polyclonal platelets and granulocytes, absence of peripheral blood dacrocytes and the JAK2 1849G $>$ T(V617F) mutation [100, 101].
Recent reports describe reversible $\mathrm{PH}$ in patients with chronic myeloid leukaemia treated with dasatinib, after discontinuation of this multi-targeted tyrosine kinase inhibitor [102, 103]. Dasatinib inhibits Bcr-Abl, Src, c-kit, and the platelet-derived growth factor (PDGF) receptor [104], Interestingly, PDGF signalling-related cellular proliferation has been suggested as an important contributor to the development and progression of PAH, and PDGF inhibition has been proposed as a possible therapeutic target in PAH $[105,106]$. Therefore, further studies are needed to better understand the link between dasatinib therapy and $\mathrm{PH}$ in these patients.

\section{Treatment}

The evidence for the effectiveness in reducing $P_{\mathrm{pa}}$ with cytoreductive therapy and haematological control of the CMPD is anecdotal. DingLi et al. [15] followed 11 of their patients with serial measurements of $P$ pa over time, and none of them showed a significant improvement despite good CMPD control. However, another case study described PH 

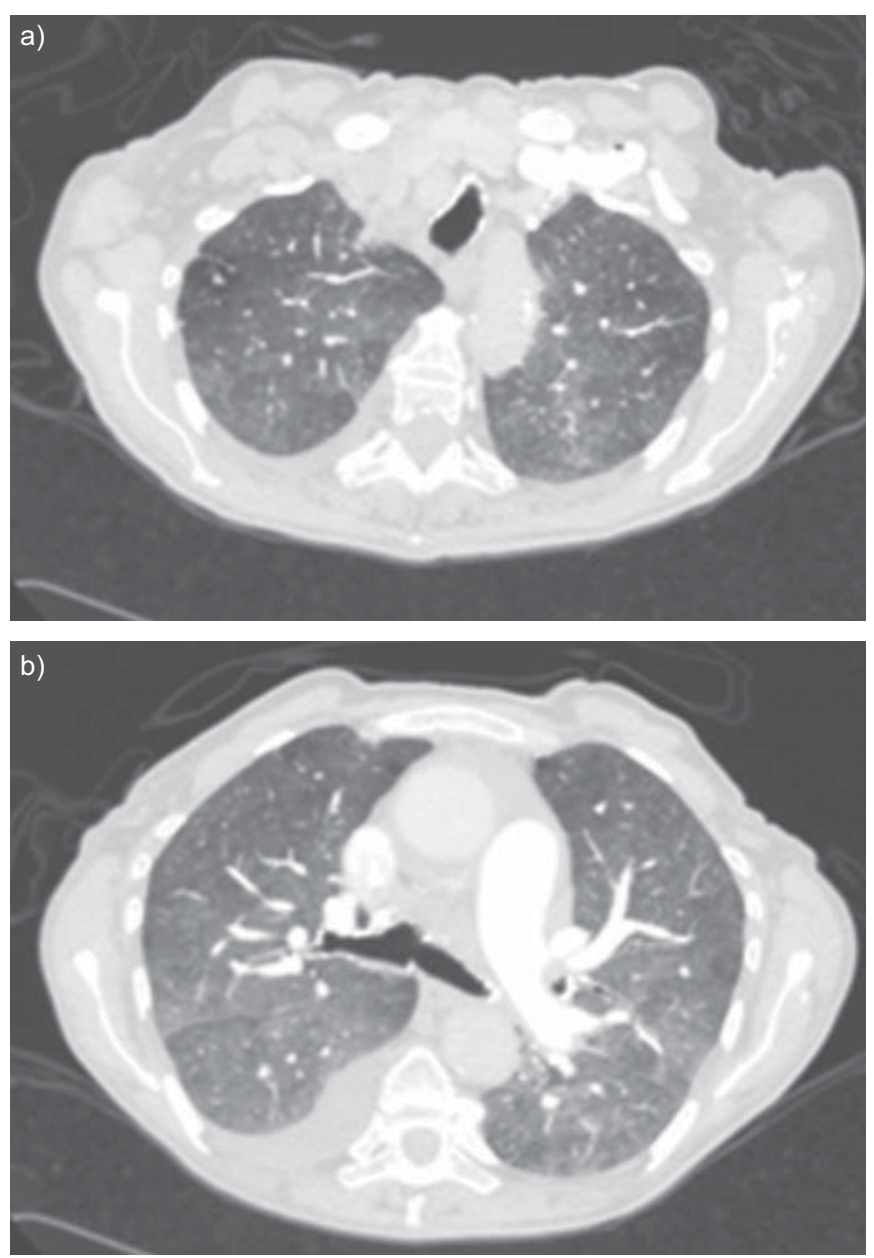

FIGURE 5. High-resolution computed tomography (CT) of the chest in a patient with pulmonary veno-occlusive disease. The CT scan shows mosaic type ground-glass opacity of both lungs which is associated with interlobular septal thickening. There is a small amount of right-side pleural effusion (b). The central pulmonary veins and left atrium are normal (not shown). The findings are highly suggestive of pulmonary veno-occlusive disease.

reversibility with cytoreductive therapy and reduction of platelet counts, or from therapeutic phlebotomies [17]. Several case reports suggest that in patients with CMPD and $\mathrm{PH}$ and evidence for extramedullar myelocytosis, a treatment trial with whole-lung, low-dose, external beam radiotherapy may be a useful palliative tool $[93,94]$. There are no data on the role of anticoagulation and anti-agregants in patients with precapillary PH associated with CMPD. However, the antithrombotic strategies in patients with polycythaemia vera and essential thrombocytosis are currently tailored on the basis of the estimated vascular risk [25].

The effectiveness of pulmonary vasodilators used for $\mathrm{PAH}$ including endothelin receptor antagonists, prostacyclin analogues and phosphodiesterase-type 5 inhibitors should be studied further.

\section{Prognosis}

The prognosis of patients with pre-capillary $\mathrm{PH}$ mimicking $\mathrm{PAH}$ associated with CMPD is poor [14-16]. In the study of
DINGLi et al. [15], the median survival time was 18 months and death was mainly related to cardiopulmonary failure. GARCIAMANERO et al. [16] reported that the interval between the development of dyspnoea (leading to the diagnosis of $\mathrm{PH}$ ) and death was $<7$ months in five out of six patients. In patients with CTEPH, pulmonary endarterectomy is the treatment of choice. In the case study by GuILPAIN et al. [14] six patients had CTEPH, including four patients with proximal disease. Three patients underwent successful endarterectomy and the fourth patient died after surgery. The two remaining patients had distal CTEPH and were treated with specific PAH therapy.

In summary, the exact incidence and prevalence of $\mathrm{PH}$ in patients with CMPD is poorly defined. Two distinct clinical forms of $\mathrm{PH}$ were described in patients with CMPD, including CTEPH and pre-capillary PH mimicking PAH. The latter cases are usually diagnosed late in the course of the haematologic disease, while CTEPH is usually diagnosed earlier. High haematocrit levels with hyperviscosity, thrombocytosis and splenectomy, among other mechanisms, may contribute to the increased rate of thrombotic events in patients with CMPD, especially polycythaemia vera. PAH-like disease associated with CMPD was found to be related to myeloid metaplasia suggesting that pulmonary myeloid infiltration and pulmonary capillary obstruction by megakaryocytes with stasis and secondary microthrombosis may contribute to the pulmonary vascular disease. Treatment of $\mathrm{PH}$ associated with CMPD is not yet established. Anticoagulant drugs should be administered carefully because of the potential risk of haemorrhagic complications. Cytoreductive treatment should be used in association with symptomatic treatment of $\mathrm{PH}$, such as oxygen and diuretics. There are no data on the effectiveness of specific $\mathrm{PAH}$ therapies in these patients and randomised control trials are needed. The prognosis of $\mathrm{PH}$ associated with CMPD remains poor. However, pulmonary endarterectomy is the treatment of choice in eligible patients with proximal CTEPH.

\section{STATEMENT OF INTEREST}

A statement of interest for M. Humbert can be found at www.erj. ersjournals.com $/ \mathrm{misc} /$ statements.dtl

\section{REFERENCES}

1 Rubin L. Primary pulmonary hypertension. N Engl J Med 1997; 336: 111-117.

2 Simonneau G, Robbins IM, Beghetti M, et al. Clinical classification of pulmonary hypertension. J Am Coll Cardiol 2009; 30: Suppl. 1, S43-S54.

3 McLaughlin VV, Archer SL, Badesch DB, et al. ACCF/AHA 2009 expert consensus document on pulmonary hypertension: a report of the American College of Cardiology Foundation Task Force on Expert Consensus Documents and the American Heart Association developed in collaboration with the American College of Chest Physicians; American Thoracic Society, Inc.; and the Pulmonary Hypertension Association. J Am Coll Cardiol 2009; 53: 1573-1619.

4 Swerdlow SH, Campo E, Harris NL, et al, eds. WHO Classification of Tumors of Haematopoietic and Lymphoid Tissues. 4th Edn. Geneva, World Health Organization, 2008.

5 Groffen J, Stephenson JR, Heisterkamp N, et al. Philadelphia chromosomal breakpoints are clustered within a limited region bcr on chromosome 22. Cell 1984; 36: 93-96. 
6 Kralovics R, Passamonti F, Buser AS, et al. A gain-of-function mutation of JAK-2 in myeloproliferative disorders. $N$ Engl J Med 2005; 352: 1779-1790.

7 Hellmann A. Myeloproliferative syndromes: diagnosis and therapeutic options. Pol Arch Med 2008; 118: 756-760.

8 Levine RL, Gilliland DG. Myeloproliferative disorders. Blood 2008; 112: 2190-2198.

9 Reisner SA, Rinkevich D, Markiewicz W, et al. Cardiac involvement in patients with myeloproliferative disorders. Am J Med 1992; 93: 498-504.

10 Garypidou V, Vakalopoulou S, Dimitriadis D, et al. Incidence of pulmonary hypertension in patients with chronic myeloproliferative disorders. Haematologica 2004; 89: 245-247.

11 Altintas A, Karahan Z, Pasa S, et al. Pulmonary hypertension in patients with essential thrombocythemia and reactive thrombocytosis. Leuk Lymphoma 2007; 48: 1981-1987.

12 Gupta R, Perumandla S, Patsiornik Y, et al. Incidence of pulmonary hypertension in patients with chronic myeloproliferative disorders. J Natl Med Assoc 2006; 98: 1779-1782.

13 Cortelezzi A, Gritti G, Del Papa N, et al. Pulmonary arterial hypertension in primary myelofibrosis is common and associated with an altered angiogenic status. Leukemia 2008; 22: 646-649.

14 Guilpain P, Montani D, Damaj G, et al. Pulmonary hypertension associated with myeloproliferative disorders: a retrospective study of ten cases. Respiration 2008; 76: 295-302.

15 Dingli D, Utz JP, Krowka MJ, et al. Unexplained pulmonary hypertension in chronic myeloproliferative disorders. Chest 2001; 120: 801-808.

16 Garcia-Manero G, Schuster SJ, Patrick H, et al. Pulmonary hypertension in patients with myelofibrosis secondary to myeloproliferative diseases. Am J Hematol 1999; 60: 130-135.

17 Marvin KS, Spellberg RD. Pulmonary hypertension secondary to thrombocytosis in a patient with myeloid metaplasia. Chest 1993; 103: 642-644.

18 Hill G, McClean D, Fraser R, et al. Pulmonary hypertension as a consequence of alveolar capillary plugging by malignant megakaryocytes in essential thrombocythaemia. Aust NZ J Med 1996; 26: 852-853.

19 Nand S, Orfei E. Pulmonary hypertension in polycythemia vera. Am J Hematol 1994; 47: 242-244.

20 Popat U, Frost A, Liu E, et al. New onset of myelofibrosis in association with pulmonary arterial hypertension. Ann Intern Med 2005; 143: 466-467.

21 Ziakas PD, Voulgarelis M, Felekouras E, et al. Myelofibrosisassociated massive splenomegaly. A cause of increased intraabdominal pressure, pulmonary hypertension, and positional dyspnea. Am J Hematol 2005; 80: 128-132.

22 Di Stefano F. Pulmonary arterial hypertension and chronic myeloproliferative disorders. Am J Respir Crit Care Med 2006; 174: 616.

23 Galiè N, Hoeper MM, Humbert M, et al. Guidelines for the diagnosis and treatment of pulmonary hypertension. Eur Respir J 2009; 34: 1219-1263.

24 Galiè N, Hoeper MM, Humbert M, et al. Guidelines for the diagnosis and treatment of pulmonary hypertension. Eur Heart $J$ 2009; 30: 2493-2537.

25 Landolfi R, Di Gennaro L, Falanga A. Thrombosis in myeloproliferative disorders: pathogenetic facts and speculation. Leukemia 2008; 22: 2020-2028.

26 Marchioli R, Finazzi G, Landolfi R, et al. Vascular and neoplastic risk in a large cohort of patients with polycythemia vera. J Clin Oncol 2005; 23: 2224-2232.

27 Wehmeier A, Daum I, Jamin H, et al. Incidence and clinical risk factors for bleeding and thrombotic complications in myeloproliferative disorders. A retrospective analysis of 260 patients. Ann Hematol 1991; 63: 101-106.
28 Gruppo Italiano Studio Policitemia. Polycythemia vera: the natural history of 1213 patients followed for 20 years. Ann Intern Med 1995; 123: 656-664.

29 Chim CS, Kwong YL, Lie AK, et al. Long-term outcome of 231 patients with essential thrombocythemia: prognostic factors for thrombosis, bleeding, myelofibrosis, and leukemia. Arch Intern Med 2005; 165: 2651-2658.

30 Besses C, Cervantes F, Pereira A, et al. Major vascular complications in essential thrombocythemia: a study of the predictive factors in a series of 148 patients. Leukemia 1999; 13: 150-154.

31 Wolanskyj AP, Schwager SM, McClure RF, et al. Essential thrombocythemia beyond the first decade: life expectancy, long-term complication rates, and prognostic factors. Mayo Clin Proc 2006; 81: 159-166.

32 Jensen MK, de Nelly Brown P, Nielsen OJ, et al. Incidence, clinical features and outcome of essential thrombocythaemia in well defined geographical area. Eur J Hematol 2000; 65: 132-139.

33 Colombi M, Radaelli F, Zocchi L, et al. Thrombotic and hemorrhagic complications in essential thrombocythemia. A retrospective study of 103 patients. Cancer 1991; 67: 2926-3290.

34 Fenaux P, Simon M, Caulier MT, et al. Clinical course of essential thrombocythemia in 147 cases. Cancer 1990; 66: 549-556.

35 Kwaan HC, Wang J. Hyperviscosity in polycythemia vera and other red cell abnormalities. Semin Thromb Hemost 2003; 29: 451-458.

36 Turitto VT, Weiss HJ. Platelet and red cell involvement in mural thrombogenesis. Ann NY Acad Sci 1983; 416: 363-376.

37 Huang PY, Hellums JD. Aggregation and disaggregation kinetics of human blood platelets: the disaggregation under shear stress of platelet aggregates. Biophys J 1993; 65: 354-361.

38 Valla D, Casadevall N, Lacombe C, et al. Primary myeloproliferative disorder and hepatic vein thrombosis. A prospective study of erythroid colony formation in vitro in 20 patients with Budd-Chiari syndrome. Ann Intern Med 1985; 103: 329-334.

39 De Stefano V, Teofili L, Leone G, et al. Spontaneous erythroid colony formation as the clue to an underlying myeloproliferative disorder in patients with Budd-Chiari syndrome or portal vein thrombosis. Semin Thromb Haemost 1997; 23: 411-418.

40 Vannucchi AM, Grossi A, Pancrazzi A, et al. PRV-1, erythroid colonies and platelet $\mathrm{Mpl}$ are unrelated to thrombosis in essential thrombocythaemia. Br J Haematol 2004; 127: 214-219.

41 Michiels JJ, Berneman Z, Bockstaele DV, et al. Clinical and laboratory features, pathology of platelet-mediated thrombosis and bleeding complications and the molecular etiology of essential thrombocythemia and polycythemia vera: therapeutic implications. Semin Thromb Hemost 2006; 32: 174-207.

42 Buss DH, Stuart JJ, Lipscomb GE. The incidence of thrombotic and hemorrhagic disorders in association with extreme thrombocytosis: an analysis of 129 cases. Am J Hematol 1985; 20: 365-372.

43 Wehmeier A, Südhoff T, Meierkord F. Relation of platelet abnormalities to thrombosis and hemorrhage in chronic myeloproliferative disorders. Semin Thromb Hemost 1997; 23: 391-402.

44 Landolfi R, Ciabattoni G, Patrignani $P$, et al. Increased thromboxane biosynthesis in patients with polycythemia vera: evidence for aspirin-suppressible platelet activation in vivo. Blood 1992; 80: 1965-1971.

45 Alvarez-Larran A, Cervantes F, Bellosillo B, et al. Essential thrombocythemia in young individuals: frequency and risk factors for vascular events and evolution to myelofibrosis in 126 patients. Leukemia 2007; 21: 1218-1223.

46 Carobbio A, Finazzi G, Guerini V, et al. Leukocytosis is a risk factor for thrombosis in essential thrombocythemia: interaction with treatment, standard risk factors and Jak2 mutation status. Blood 2007; 109: 2310-2313.

47 Baxter EJ, Scott LM, Campbell PJ, et al. Acquired mutation of the tyrosine kinase JAK2 in human myeloproliferative disorders. Lancet 2005; 365: 1054-1061. 
48 James C, Ugo V, Le Couedic JP, et al. A unique clonal JAK2 mutation leading to constitutive signalling causes polycythaemia vera. Nature 2005; 434: 1144-1148.

49 Cazzola M, Skoda R. Gain of function, loss of control F a molecular basis for chronic myeloproliferative disorders. Haematologica 2005; 90: 871-874.

50 Campbell PJ, Scott LM, Buck G, et al. Definition of subtypes of essential thrombocythaemia and relation to polycythaemia vera based on JAK2 V617F mutation status: a prospective study. Lancet 2005; 366: 1945-1953.

51 Arellano-Rodrigo E, Alvarez-Larran A, Reverter JC, et al. Increased platelet and leukocyte activation as contributing mechanisms for thrombosis in essential thrombocythemia and correlation with the JAK2 mutational status. Haematologica 2006 91: 169-175.

52 Falanga A, Marchetti M, Vignoli A, et al. V617F JAK-2 mutation in patients with essential thrombocythemia: relation to platelet, granulocyte, and plasma hemostatic and inflammatory molecules. Exp Hematol 2007; 35: 702-711.

53 Kiladjian JJ, Cervantes F, Leebeek FW, et al. The impact of JAK2 and MPL mutations on diagnosis and prognosis of splanchnic vein thrombosis. A report on 241 cases. Blood 2008; 111: 4922-4929.

54 Pardanani A, Lasho TL, Hussein K, et al. JAK2V617F mutation screening as part of the hypercoagulable work-up in the absence of splanchnic venous thrombosis or overt myeloproliferative neoplasm: assessment of value in a series of 664 consecutive patients. Mayo Clin Proc 2008; 83: 457-459.

55 Hirsch J, Dacie V. Persistent post-splenectomy thrombocytosis and thrombo-embolism: a consequence of continuing anemia. $\mathrm{Br}$ J Haematol 1966; 12: 44-53.

56 Mohren M, Markmann I, Dworschak U, et al. Thromboembolic complications after splenectomy for hematologic diseases. Am J Hematol 2004; 76: 143-146.

57 Chaffanjon CJ, Brichon $\mathrm{P}$, Ranchoup $\mathrm{Y}$, et al. Portal vein thrombosis following splenectomy for hematologic disease: prospective study with Doppler color flow imaging. World J Surg 1998; 22: 1082-1086.

58 Van't riet M, Burger J, Van Muiswinkel JM, et al. Diagnosis and treatment of portal vein thrombosis following splenectomy. $\mathrm{Br}$ Surg 2000; 87: 1229-1233.

59 Tefferi A, Mesa R, Nagorney DM, et al. Splenectomy in myelofibrosis with myeloid metaplasia: a single-institution experience with 223 patients. Blood 2000; 95: 2226-2233.

60 Bonderman D, Wilkens H, Wakounig S, et al. Risk factors for chronic thromboembolic pulmonary hypertension. Eur Respir J 2009; 33: 325-331.

61 Jais X, Ioos V, Jardim C, et al. Splenectomy and chronic thromboembolic pulmonary hypertension. Thorax 2005; 60: 1031-1034.

62 Boxer MA, Braun J, Ellman L. Thromboembolic risk of postsplenectomy thrombocytosis. Arch Surg 1978; 113: 808-809.

63 Visudhiphan S, Ketsa-Ard K, Piankijagun A, et al. Blood coagulation and platelet profiles in persistent post splenectomy thrombocytosis. The relationship to thromboembolism. Biomed Pharmacother 1985; 39: 264-271.

64 Kuypers FA, Yuan J, Lewis RA, et al. Membrane phospholipids asymmetry in human thalassemia. Blood 1998; 91: 3044-3051.

65 Atichartakarn V, Angchaisuksiri P, Aryurachai $\mathrm{K}$, et al. Relationship between hypercoagulable state and erythrocyte phosphatidylserine exposure in splenectomized haemoglobin E/ b-thalassemic patients. Br J Haematol 2002; 118: 893-898.

66 Hirsh J, Guyatt G, Albers GW, et al. Antithrombotic and thrombolytic therapy: American College of Chest Physicians Evidence-Based Clinical Practice Guidelines (8th Edition). Chest 2008; 133: Suppl. 6, 110-112.

67 Cappellini MP, Grespi E, Cassinerio E, et al. Coagulation and splenectomy: an overview. Ann NY Acad Sci 2005; 1054: 317-324.
68 Fedullo PF, Auger WR, Kerr KM, et al. Chronic thromboembolic pulmonary hypertension. N Engl J Med 2001; 345: 1465-1472.

69 Hughes RJ, Jais X, Bonderman D, et al. The efficacy of bosentan in inoperable chronic thromboembolic pulmonary hypertension: a 1-year follow-up study. Eur Respir J 2006; 28: 138-143.

70 Seyfarth HJ, Hammerschmidt S, Pankau H, et al. Long-term bosentan in chronic thromboembolic pulmonary hypertension. Respiration 2007; 74: 287-292.

71 Nagaya N, Sasaki N, Ando M, et al. Prostacyclin therapy before pulmonary thromboendarterectomy in patients with chronic thromboembolic pulmonary hypertension. Chest 2003; 123: 338-343.

72 Olschewski H, Simonneau G, Galie N, et al. Inhaled iloprost for severe pulmonary hypertension. N Engl J Med 2002; 347: 322-329.

73 Wilkins MR, Wharton J, Grimminger F, et al. Phosphodiesterase inhibitors for the treatment of pulmonary hypertension. Eur Respir J 2008; 32: 198-209.

74 Reichenberger F, Voswinckel R, Enke B, et al. Long-term treatment with sildenafil in chronic thromboembolic pulmonary hypertension. Eur Respir J 2008; 31: 759-764.

75 Cortelazzo S, Finazzi G, Ruggeri M, et al. Hydroxyurea for patients with essential thrombocythemia and a high risk of thrombosis. N Engl J Med 1995; 332: 1132-1136.

76 Fruchtman SM, Mack K, Kaplan ME, et al. From efficacy to safety: a polycythemia vera study group report on hydroxyurea in patients with polycythemia vera. Semin Hematol 1997; 34: 17-23.

77 Harrison CN, Campbell PJ, Buck G, et al. Hydroxyurea compared with anagrelide in high-risk essential thrombocythemia. $N$ Engl J Med 2005; 353: 33-45.

78 Maugeri N, Giordano G, Petrilli MP, et al. Inhibition of tissue factor expression by hydroxyurea in polymorphonuclear leukocytes from patients with myeloproliferative disorders: a new effect for an old drug? J Thromb Haemost 2006; 4: 2593-2598.

79 Landolfi R, Marchioli R, Kutti J, et al. Efficacy and safety of low dose aspirin in polycythemia vera. N Engl J Med 2004; 350: 114-124.

80 Van Genderen PJ, Mulder PG, Waleboer M, et al. Prevention and treatment of thrombotic complications in essential thrombocythaemia: efficacy and safety of aspirin. Br J Haematol 1997; 97: 179-184.

81 Ito H, Adachi Y, Arimura Y, et al. A 25-year clinical history of portopulmonary hypertension associated with latent myeloproliferative disorder. J Gastroenterol 2003; 38: 488-492.

82 Tefferi A. Myelofibrosis with myeloid metaplasia. N Engl J Med 2000; 342: 1255-1265.

83 Ward HP, Block MH. The natural history of agnogenic myeloid metaplasia (AMM) and a critical evaluation of its relationship with the myeloproliferative syndrome. Medicine (Baltimore) 1971; 50: 357-420.

84 Montani D, Price LC, Dorfmuller P, et al. Pulmonary venoocclusive disease. Eur Respir J 2009; 33: 189-200.

85 Willems E, Canivet JL, Ghaye B, et al. Pulmonary veno-occlusive disease in myeloproliferative disorder. Eur Respir J 2009; 33: 213-216.

86 Adir Y, Yigla M, Amir O, et al. Pulmonary hypertension associated with myeloproliferative disorders suggesting pulmonary veno-occlusive disease: a retrospective study of six cases. Eur Respir J 2009; 34: Suppl. 53, 319s.

87 Halank M, Marx C, Baretton G, et al. Severe pulmonary hypertension in chronic idiopathic myelofibrosis. Onkologie 2004; 27: 472-474.

88 Hill G, McClean D, Fraser R, et al. Pulmonary hypertension as a consequence of alveolar capillary plugging by malignant megakaryocytes in essential thrombocythaemia. Aust NZ J Med 1996; 26: 852-853.

89 Dot JM, Sztrymf B, Yaïci A, et al. Pulmonary arterial hypertension due to tumor emboli. Rev Mal Respir 2007; 24: 359-366.

90 Hibbin JA, Njoku OS, Matutes E, et al. Myeloid progenitor cells in the circulation of patients with myelofibrosis and other myeloproliferative disorders. Br J Haematol 1984; 57: 495-503. 
91 Haznedaroglu IC, Atalar E, Ozturk MA, et al. Thrombopoietin inside the pulmonary vessels in patients with and without pulmonary hypertension. Platelets 2002; 13: 395-399.

92 Koch CA, Li CY, Mesa RA, et al. Nonhepatosplenic extramedullary hematopoiesis: associated diseases, pathology, clinical course, and treatment. Mayo Clin Proc 2003; 78: 1223-1233.

93 Steensma DP, Hook CC, Stafford SL, et al. Low-dose, single fraction, whole-lung radiotherapy for pulmonary hypertension associated with myelofibrosis with myeloid metaplasia. $\mathrm{Br} \mathrm{J}$ Haematol 2002; 118: 813-816.

94 Weinschenker P, Kutner JM, Salvajoli JV, et al. Whole-pulmonary low-dose radiation therapy in agnogenic myeloid metaplasia with diffuse lung involvement. Am J Hematol 2002; 69: 277-280.

95 Neville RF, Sidawy AN. Myointimal hyperplasia: basic science and clinical considerations. Semin Vasc Surg 1998; 11: 142-148.

96 Perros F, Montani D, Dorfmüller P, et al. Platelet-derived growth factor expression and function in idiopathic pulmonary arterial hypertension. Am J Respir Crit Care Med 2008; 178: 81-88.

97 White SM, Wagner JG, Roth RA. Effects of altered platelet number on pulmonary hypertension and platelet sequestration in monocrotaline pyrrole-treated rats. Toxicol Appl Pharmacol 1989; 99: 302-313.

98 Zetterberg E, Popat U, Hasselbalch H, et al. Angiogenesis in pulmonary hypertension with myelofibrosis. Haematologica 2008; 93: 945-946.
99 Cortelezzi A, Gritti G, Del Papa N, et al. Pulmonary arterial hypertension in primary myelofibrosis is common and associated with an altered angiogenic status. Leukemia 2008; 22: 646-649.

100 Popat U, Frost A, Liu E, et al. High levels of circulating CD34 cells, dacrocytes, clonal hematopoiesis, and JAK2 mutation differentiate myelofibrosis with myeloid metaplasia from secondary myelofibrosis associated with pulmonary hypertension. Blood 2006; 107: 3486-3488.

101 Fadini GP, Schiavon M, Cantini M, et al. Circulating D34+ cells, pulmonary hypertension, and myelofibrosis. Blood 2006; 108 1776-1777.

102 Quintas-Cardama A, Kantarjian H, O'Brien S, et al. Pleural effusion in patients with chronic myelogenous leukemia treated with dasatinib after imatinib failure. J Clin Oncol 2007; 25: 3908-3914.

103 Rasheed W, Flaim B, Seymour J. Reversible severe pulmonary hypertension secondary to dasatinib in a patient with chronic myeloid leukaemia. Leuk Res 2009; 33: 861-864.

104 O'Hare T, Walters DK, Stoffregen EP, et al. In vitro activity of Bcr-Abl inhibitors AMN107 and BMS-354825 against clinically relevant imatinib-resistant Abl kinase domain mutants. Cancer Res 2005; 65: 4500-4505.

105 Souza R, Sitbon O, Parent F, et al. Long term imatinib treatment in pulmonary arterial hypertension. Thorax 2006; 61: 736.

106 Ghofrani HA, Seeger W, Grimminger F. Imatinib for the treatment of pulmonaryarterial hypertension. $N$ Engl J Med 2005; 353: 1412-1413. 